\title{
An exploration of the potential of WWW current awareness services for oncology nurses
}

Ina Fourie

Retha Claasen-Veldsman

Ina Fourie, Department of Information Science, University of Pretoria, Pretoria, South Africa

Retha Claasen-Veldsman, Department of Information Science, University of Pretoria, Pretoria, South Africa

\section{[Figure at the bottom of document]}

Purpose - The potential of current awareness services (CAS) for oncology nurses is considered with special reference to the spectrum of WWW CAS that are available, their benefits and problems, and how these can be linked to the dynamic health environments in which oncology nurses may find themselves. The intention with the article is to show the need for exploring the value of WWW CAS for dynamic professional fields such as oncology nursing, and to offer a point of departure for research on their information behaviour. The WWW CAS that were identified might be used to get oncology nurses interested in using such services, as well as in participating in research on their information behaviour.

Design/methodology/approach - A literature study on the nature and value of CAS is combined with a cursory analysis of the literature of oncology nursing to provide insight into the professional demands that oncology nurses need to cope with, and the potential value of CAS for oncology nurses. Based on this a selection of WWW CAS suitable for oncology nurses is identified. Insight into the potential of WWW CAS for oncology nurses and the CAS that are available are combined with what can be learned from studies on information-seeking behaviour to offer some suggestions on how the need for oncology nurses to use CAS available via the WWW can be further explored. In general the suggestions to explore the use of CAS would also apply to other professional fields.

Findings - It seems as if oncology nurses can benefit substantially from WWW CAS. To successfully implement such CAS, extensive research on the information-seeking behaviour, information use and information communication of oncology nurses is, however, necessary. The article could be used as an instrument to gain oncology nurses' interest in WWW CAS, and willingness to participate in further research on their information needs and information behaviour.

Practical implications - Oncology nurses' interest in CAS can be stimulated, and the article can be used as point of departure for further research. The article can also offer 
new opportunities for library and information (LIS) professionals to offer CAS in the health and other professional sectors, by reconsidering how one can use CAS available via the WWW.

Originality/value - No reports on CAS for oncology nurses could be traced, and there are also very few reports on the information needs and information behaviour of oncology nurses. The article hopes to pave the way for renewed interest in using CAS in demanding professional environments, and especially the health sciences, as well as to stimulate interest in research in information-seeking behaviour in the health sciences.

\section{Introduction}

Present-day society is marked by many professional environments that experience increasing pressure in terms of competition, productiveness, client expectations, etc. Due to the increase in access to the worldwide web (WWW) from all sectors of society, as well as current awareness services (CAS) available via the WWW, it seems timely to explore what is available for professions such as oncology nursing that are considered to be very dynamic and where funding to use commercial CAS might be a problem.

If information to keep track of one's professional field is freely available, why not use it? This may seem like a simple argument from an academic and theoretical point of view, especially if one is au fait with the arguments for using CAS. However, by informally observing the day-to-day tasks of a group of nurses at an oncology clinic and oncology hospital ward in South Africa, the authors became intensely aware of the additional challenges one faces when working with cancer patients. As the result of long hours, spending most of the day on their feet, and having hardly a moment for themselves between the demands of patients, their family and friends, doctors (oncologists) and other team members such as pathologists, dieticians, social workers and physiotherapists, keeping abreast of their field is probably the last thing oncology nurses may have on their minds, especially if one adds the emotional burden of supporting patients and their family/friends to cope with the threats and realities of death. When considering the demands of their tasks, we also became convinced of the value CAS may have for oncology nurses. In order to gain their interest in using CAS and to participate in research on information-seeking behaviour, the authors decided first to explore what is available via the WWW, as well as to look at the challenges that oncology nurses are facing according to their subject literature.

A selection of WWW CAS available to oncology nurses, as well as how they can expect to benefit form these, are therefore explored in this article as background to general suggestions on how to continue with further research on the information needs and the information seeking behaviour of oncology nurses. Although we focus on oncology nurses, we hope that the article will also stimulate interest in re-exploring the possibilities that the WWW offers for CAS to basically any professional environment. We are fully aware that CAS is not a new concept in the LIS literature, but believe that LIS professionals should increase efforts to explore the power of WWW CAS (available for 
free) and its ability to partially address unequal access to current information. The more we can learn from the information seeking behaviour of people from all spectrums of life, the better our understanding to develop information retrieval systems and information services (including CAS).

In this article we will consider the following:

- a revised look at CAS and the value it may hold for oncology nurses;

- a brief overview of the challenges faced by oncology nurses and the potential information needs that may be derived from their subject literature;

- literature review of the information seeking behaviour and information needs of oncology nurses, and nurses in general;

- discussion of a selection of WWW CAS considered appropriate for oncology nurses; and

- suggestions on exploring the information seeking behaviour of oncology nurses and their use of WWW CAS.

\section{Background on oncology nursing}

Oncology is the field of medicine devoted to cancer and the study of tumors (MedicineNet.com, 2003). Oncology nursing concerns the nursing of cancer patients. Nursing Spectrum (2004), for example, explains an oncology nurse as someone who "cares for patients with the diagnosis of cancer in various settings; utilizes an emphatic and caring approach to patients whose diagnosis and treatment are often painful and lifethreatening; administers chemotherapy, conducts patient teaching, and manages illnessand treatment-related symptoms”.

Similar to other fields in the health services, oncology nursing is marked by a rapidly changing, ever more demanding environment. Baker and Fitch (cited by Browne et al., 2002, p. 134) capture this very well. "Throughout Europe cancer nurses are striving to meet the challenges of providing quality nursing care amid changing environments that are characterized by advances in drugs and technologies, ageing populations, increasing rates of cancer, increased survival rates, rising costs and increasing economic constraints".

Walton (2004) also stresses the dynamic and rapidly evolving environment of health related services. He stresses trends towards patient empowerment, new roles for health clinicians and new working practices: "Changes in roles are accompanied by pressures for clinicians to develop different working practices. Multidisciplinary teamwork encourages nurses to work in partnership with domestic and support staff to improve the ward environment. This 'new professionalism' embraces care based on 'shared practice, knowledge and values rather than differences based on jealously guarded systems of regulation, education and pay'” (Walton, 2004, p. 4). Walton (2004) advises librarians to revise and develop information services to accommodate such developments. It seems 
as if it might become more important for oncology nurses to collaborate - also with team players from other disciplines, which may again imply the need for an increased awareness of the subject literature of related fields.

The rapidly changing occupational environment of oncology nurses is marked by globalisation, IT developments, and especially access to the worldwide web (WWW). For example, a number of current awareness services (CAS) are also available through the WWW.

Due to the limited scope of reported evidence on the information seeking behaviour of oncology nurses and their perceived information needs, the authors decided to use this article to explore the possibilities for WWW CAS for oncology nurses by first looking at information needs that are implied by the oncology nursing literature and what we know about the reasons for using CAS. This will be followed by exploring WWW CAS that are available for free to oncology nurses.

\section{Current awareness services (CAS)}

Current awareness is the awareness (i.e. taking note) of the latest developments by noting information that has recently become available. Information can be available in different formats (e.g. printed format, electronic format, audio, video, multimedia, etc.). Information can be made available through books, journal articles, conferences, reports, theses, workshops, seminars, videos, websites, discussion groups, etc. Formal as well as informal methods of information dissemination can be used. A variety of types of CAS are available to help people note information as soon as it becomes available, and to offer access to the information (Fourie, 1999).

CAS, also called selective dissemination of information services (SDI), alerting services, alerts, current alerting services, and individual article supply, have been offered over many years by libraries and information services (LIS). In 1958, H.P. Luhn was the first to propose the use of computers for CAS (Housman, 1973). The principles for offering CAS, as well as services to specific user groups, have been well explored by, for example, Kemp (1979), Whitehall (1982), Rowley (1998), and Hamilton (1995). Several editions of the Handbook of Special Librarianship and Information Work have also included contributions on CAS or the dissemination of information (e.g. Trench, 1997; Whitehall, 1982). Fourie (2001) added to this in the eighth edition (titled Handbook of Information Management). Several review articles on CAS have also appeared in the Annual Review of Information Science and Technology (e.g. Housman, 1973). Although CAS is certainly not a new concept, no reported evidence could be traced of CAS for oncology nurses. It is also the authors' perception that there might be professionals from many other fields who can benefit if we reconsider their use of CAS by looking at what is offered for free via the WWW. It is furthermore our perception that the value of CAS is not nearly fully exploited and that many challenges still lie in 
addressing the typical problems of CAS, such as information overload and information anxiety, as well as how CAS can contribute to innovation, etc.

CAS were originally introduced to help library users keep track of trends in highly specialized fields of interest. They were often expensive and/or required the help of librarians and information specialists. Since there is more information available for free via the WWW, it is no longer only the elite who can pay for information who are able to keep abreast, but also people who realize the importance of information, who are able to identify appropriate services, and who have the skills and know-how to use these. Unfortunately time often seems to inhibit the use of CAS. Nesbeitt and Gordon's (2002, p. 52) counter-argument is: "whereas before I might have thought of it as 'I don't have time to keep up', I started to realize I don't have time not to keep up!” Although the potential might be there for oncology nurses to use WWW CAS, it does not speak for itself that they will have the time for or interest in doing so.

We therefore decided to reconsider the "traditional" reasons for offering CAS and to link these to information needs that could be derived by considering the subject literature of oncology nursing. Fourie (2001, pp. 279-80) lists some of the traditional benefits of CAS, such as keeping track of new developments in a field, new research projects, new websites, discussion groups or publications and internet-related developments. It can also help in noting daily news events, marketing developments and forthcoming events, and supporting productivity in terms of research and publications.

The list should, however, be adapted for specific occupations or workplace environments, such as oncology nursing. For this article we took as point of departure a cursory overview of the oncology nursing literature.

When considering the value of WWW CAS, one should also be aware of the many obstacles one may face. These include the time required to identify appropriate CAS services and the time required to work through the information and to organize and manage the information. It also includes the time and effort required in obtaining full-text articles. Information overload can also be experienced, which might lead to stress and anxiety. If not well-managed and appropriately used, the information noted through CAS can easily turn into a nightmare, adding to the challenges (or burden) of keeping up with a job that are already challenging - both physically and emotionally.

Regardless of how well the use of CAS can be motivated, people need to accept this first and agree to try CAS out; people such as oncology nurses can be motivated, but not forced, to use CAS. As already explained, the purpose of this article is to pave the way for such motivation. Before considering the potential information needs of oncology nurses, we will briefly look at research reported on their information seeking behaviour. 


\section{Information-seeking behaviour of oncology nurses}

A literature search provided little insight into the information needs of oncology nurses, and nothing could be traced on the provision of CAS for oncology nurses. A wide variety of databases in the field of information science, nursing and medicine were searched.

Fitch et al. (1998) report on one of very few studies on the information needs of oncology nurses. They considered the information needs with regard to breast diseases. Most of the nurses in their survey felt that they experienced no gap in their knowledge, and therefore did not need information. This is interesting if one considers the complaints often raised by patients that they do not receive enough information. A survey on how oncology nurses use the internet is reported by Cobb and Baird (1999). Their survey determined that oncology nurses use the internet for drug information, literature searches, academic information, patient education, and continuing education.

There is, however, slightly more information available on the information needs of nurses in general. In an early study, Wakeham (1992) found that nursing students are not readers and that they prefer to consult with colleagues to satisfy their information needs. However, in later studies there seems to be some interest in information seeking. Verhey (1999) discusses information literacy as part of an undergraduate nursing curriculum, French (1998) relates information seeking to decision-making in evidence-based practices, Sundin (2002) reports nurses' information seeking and use as participation in occupational communities, while Cogdill (2003) focuses on primary care nursing practitioners. Urquhart and Crane (1994) also report on nurses' information-seeking skills and perceptions of information sources, while Barta (1995) reports on the information seeking of pediatric nurse educators.

A number of publications have also appeared on cancer patients' need for information. In certain cases this can be linked to the patient educational function of nurses, for example as reported by Echlin and Ress (2002), Hughes et al. (2000), Thomson (2000), Mahon and Williams (2000), Tarzian et al. (1999), Van der Molen (1999), and Hartigan (2003). We would expect that there is certainly a need for oncology nurses to note reports on the information seeking behaviour of cancer patients and their needs, and how this may affect their own task.

\section{Challenges faced by oncology nurses and potential information needs}

Oncology nurses find themselves in a rapidly evolving health environment, with increased demand for their services, due to the ageing population and number of HIVpositive patients who often develop secondary cancer. Some of the challenges faced by oncology nurses include new educational methods and societal expectations, emphasis on life-long learning and continuing professional development, greater pressure for job performance, and changing communication methods and methods for information 
dissemination. According to Jenkins (1997) health care providers are experiencing significant changes in their professional lives: apart from the changing environment there is a need for consumers to be knowledgeable and the expectations of care providers are enhanced. There seems to be especially an importance to genetic discoveries influencing available health care and the educational preparation of patients. Schlachta-Fairchild (2001), for example, reports on the use of telehealth as a new method for health care delivery.

Oncology nurses are expected to show excellence in patient care, education, research, and oncology administration. According to the Oncology Nursing Society (ONS), they require clinical, educational and inspirational publications. They need to access cuttingedge information and "encourage narratives" (see www.ons.org). Mooney (2004, p. 74) adds to this: "In the end, cancer patients suffer when nurses can not practice to their full potential”.

More specifically it was noted from the literature (Anderson and Bruce, 2002; Jenkins, 1997) that oncology nurses need amongst other things, to note developments and trends concerning a number of broad categories. The following is intended as a guideline only to stimulate discussions with oncology nurses on their specific information interests. The intention is also not for individual nurses to keep track of developments concerning all these categories, but to try to work out something where they can benefit from multidisciplinary teamwork (e.g. including dieticians, social workers), and collaborative use and seeking of information.

\section{Career development}

- Trends requiring reconsideration of their roles.

- New identified roles (e.g. counseling in cancer genetics risks), and how to prepare for these.

- Training and continuing professional development opportunities (e.g. workshops, seminars, conferences).

\section{Pressure for improved health care}

- Contribution nurses can make to cancer care and the growing expectations from the health care sector and public at large.

- Innovative application of nursing skills and talents to improve the care of cancer patients.

- Symptom management, particularly of pain, nausea and vomiting, and fatigue.

\section{Need for patient education and information support}

- Information needs of patients (as reported in the subject literature). 
- Practices in patient education.

- Needs of patients related to communication.

- Patients' experiences of diseases and its treatment, with a particular focus on psychological experiences.

\section{Occupational environment}

- Barriers to their work as well as trends or practices that present barriers (e.g. dealing with medication errors).

- Safety of oncology nursing practice.

- Concerns about the workplace environment.

\section{Societal trends}

- Societal expectations for oncology nursing practice.

- Ethical dilemmas and dealing with these (e.g. requests for patient assisted suicide).

- Trend towards collaboration and partnership.

- Ageing population.

- Increase in number of cancer patients (also because of HIV patients developing secondary cancer).

- Impact of globalisation.

- $\quad$ Pressure for evidence based practice.

- Political impacts.

- Pressure for local accountability.

- Pressure for quality control.

- Impact of economic factors.

\section{Research priorities and practice}

- As noted in the subject literature.

- As can be derived from other aspects that are monitored.

- Reports of evidence based practice.

- Cancer nursing research issues, such as research facilitation and utilization.

\section{Administration}

- Guidelines for administrators and managers in creating an environment where oncology nursing can thrive. 


\section{Problem solving}

- Suggestions and strategies to solve problems concerning oncology nursing.

\section{Educational issues}

- Education and teaching needs and priorities that should be addressed through training interventions.

- Cancer nursing education issues such as nurses' educational needs.

\section{Organisational trends}

- Changes in institutional or workplace policy.

- Organisational administrative developments.

\section{Resources available to patients}

- Community resources available to patients.

- Other forms of support available (e.g. websites, discussion lists, support groups it might be argued whether this is the responsibility of oncology nurses or social workers).

\section{IT developments}

- Impact of IT (e.g. telehealth, electronic patient records).

- New methods for communication (e.g. teleconferencing, video conferences, virtual conferences).

- New methods for information dissemination (e.g. WWW discussion lists, WWW CAS, electronic journals).

- Extended access cancer patients may have to WWW resources.

A review by Browne et al. (2002), for example, reports the following findings with regard to research priorities. The category ranked most highly in respondents' top five priorities concerned patients' needs regarding communication, information-giving and education. The category ranked second includes research questions on the facilitation of cancer nursing research and the utilization of research findings in practice. Nursing education also ranked high.

According to Mooney (2004), position papers, often available through professional societies, can especially be useful sources of information. "Professional practice position papers can promote the role of the oncology nurse, can address barriers to professional practice, and can provide guidance on ethical conduct. They are not only helpful for 
advocating policy change with governmental and regulatory bodies, but nurses can use them to directly improve their work environment” (Mooney, 2004, p. 76).

\section{Selected services considered useful to oncology nurses}

There are many CAS available via the WWW. These go under different names (e.g. tables of content, intelligent agents, push services, webcasting). Some of these services are available for free or at a modest fee, while others are very expensive and definitely aimed at the corporate market.

Fourie (2003) suggests a number of services. Nesbeitt and Gordon (2002) expanded on these services. They also declare: "These days, it can be said that keeping up with even current awareness resources in the information profession has become an issue" (Nesbeitt and Gordon, 2002, p. 52).

In this article the following WWW CAS are considered:

- $\quad$ tables of contents services (TOCs) (mostly associated with journals);

- book alerting services (including book announcements and tables of contents);

- $\quad$ article alerting services, including commercial SDI;

- electronic newsletters;

- conference announcements;

- WWW discussion groups and electronic mailing lists; and

- web pages with newsworthy content.

There are also other forms of WWW CAS, such as push technology, weblogs, newspapers and newspaper alerts and website update notification services. These will, however, not be dealt with in this article. Each type of service will now be briefly explained. A very limited list of examples of each is provided in the Appendix: it is not the purpose of this article to offer an exhaustive list.

\section{Tables of contents (TOC) and tables of contents services (TOCS)}

Monitoring the tables of contents of key journals can be a very useful way of keeping track of the latest articles, especially if the journals have a web presence. Although the full-text articles are not available for free, there is no cost to looking at the table of contents. There are two ways in which tables of contents can be monitored:

1. sporadic checking of the website for the latest journal edition and the table of contents; and

2. automatic e-mail notification of the table of contents as soon as the latest journal edition is available (these are now often also available through RSS feeds). 
Tables of contents can also be monitored through subscription to TOCS (e.g. Ingenta), or through subscription to aggregator services offering an alerting service (e.g.

ScienceDirect). (For the latter a condition will be that these services do cover the journals relevant to oncology nursing.)

\section{Book alerting services}

Book alerting services will include book announcement services and services offering access to the tables of content of books. It can include a brief description of new books and sometimes also the table of contents or preliminary overview of the content. Many useful publications are also available from professional societies, for example Access Device Guidelines: Recommendations for Nursing Practice and Education, and Peripheral Blood Stem Cell Transplantation: Recommendations for Nursing Education and Practice, which are published by the Oncology Nursing Society (ONS).

\section{Article alerting services, including commercial SDI}

Article alerting services and selective dissemination of information (SDI) services involve the automatic notification of users when new records are added to a database or aggregator service. The records are matched against a search strategy reflecting the user's search profile. These services are only available via subscription and can be very expensive.

\section{Electronic newsletters}

Electronic newsletters offer a very useful method of current awareness. Such newsletters can be available through professional organizations, and although they are sometimes available to members only, there are newsletters that are freely available.

\section{Conference announcements}

Professional conferences are excellent ways to monitor new developments. To attend or submit papers, however, one needs to take note of the call for papers and registration.

\section{WWW discussion groups and electronic mailing lists}

Discussion groups are very useful, but can easily lead to information overload. Such groups are often linked to professional organizations. 


\section{Web pages with newsworthy content}

There are many websites containing useful information, for example the websites of professional organizations. Although very time-consuming, it might be worthwhile to monitor such sites on a regular basis. A few examples are provided in the Appendix.

\section{Collecting data about oncology nurses' needs for CAS}

As we have already pointed out, oncology nurses find themselves in a rapidly changing environment, which poses ongoing challenges and a need for information to stay abreast of developments and expectations - some of which are discussed in this article. This will lead to what Dervin (1999) refers to as a gap between what is known and what needs to be known in order to make sense of a situation. She depicts this as a triangle consisting of a situation in which the person needs to make sense, a gap that needs to be bridged, and the outcome (use of information).

In order to exploit available CAS successfully to bridge this gap or to develop an integrated CAS, a number of issues will require further attention. We need to learn more about the situation in which oncology nurses find themselves (e.g. job and requirements from the profession, management's expectations as well as the expectations of cancer patients). We also need to learn more about how they experience this "gap" between what they know and what they need to know, and whether they are at all aware of such a gap.

Research on information-seeking behaviour is therefore necessary to learn more about the current information needs and information behaviour of oncology nurses. Data can be collected by means of questionnaires in combination with individual and focus group interviews, observation and transaction logs. When collecting data the following need to be considered amongst other things:

- $\quad$ access to traditional information services (e.g. as in libraries or information services);

- $\quad$ access to the WWW;

- computer and information literacy, and especially skills in using the WWW;

- need for information: retrospective, factual, as well as current awareness;

- $\quad$ preferences for information sources (e.g. books, journal articles, conference papers);

- current use of services: why people use services, which services they are using, why people are not using services, and why some people are more inclined to use the services: Pantry and Griffiths (2002), for example, distinguish different categories of e-service users - those who never use information, those who are timid users of the system who would like to make more use of the system, those who are sporadic users and typically believe that they have all the information they need, and those devoted users who make full use of the service; 
- nurses' knowledge of the oncology nursing information infrastructure (e.g. key journals, publishers, professional associations, conferences, discussion lists, etc.);

- work positions and tasks related to position (e.g. nurse, sister, unit manager);

- motivational factors (e.g. publishing, conference attendance, involvement in local professional society, internal awards and promotion, patient gratitude);

- feelings about CAS (e.g. interested, skeptical);

- awareness of problems that can be expected such as the need for further filtering, information overload, the fact that many of the services are time-intensive to monitor, and that many of the services available on the WWW for free are not tailor-made for the target group or as CAS;

- expectations on benefiting from CAS; and

- experience of collaborative work and information searching: this might potentially offer a way to deal with information overload, and need to be further explored in the light of the growing interest in collaborative information seeking, for example, as reported by Fidel et al. (2000), Prekop (2002), Hansen and Järvelin (2005) and Hyldegård (2006).

The need to know more about the above-mentioned aspects can be derived from the extensive literature on information seeking behaviour such as the research reports captured by Case (2002), Spink and Jansen (2004), Kuhlthau (2004) and Vakkari (2003). Fourie (2002, 2004) also reviews the literature on web information seeking studies.

The next step will be to match the information needs against the available WWW CAS infrastructure. Although a selection of CAS are identified in this article (see the Appendix), there are many more to consider. The implications of using each of these, for example using tables of contents, need to be considered and mapped against the needs of oncology nurses and how they may hope to gain from the information.

None of the CAS mentioned in this article will offer updates on all the information oncology nurses need to note. It is therefore necessary to use a combination of CAS. Merely identifying a list of CAS examples and matching these against perceived needs is therefore not enough. We need to go further in researching the development of integrated CAS meeting with the information seeking behaviour of the specific user group, in this case oncology nurses. Oncology nurses can use CAS as individuals or they can be set up by an oncology unit for a group of nurses. Professional societies for oncology nurses can also set up a website with links to relevant CAS which nurses can use, for example, to monitor conference calls for papers, or subscribe to e-mail notification services. It is essential to involve LIS professionals in setting up such CAS. The offering of CAS to oncology nurses also offer exciting challenges to LIS professionals to explore the information needs of oncology nurses to keep abreast, as well as to come up with innovative methods to deal with the problems of CAS such as information overload and the need to stimulate effective information use. 


\section{Conclusion}

CAS can open new horizons to oncology nurses, and can assist them in their striving to keep up with the dynamic health environment and demands for quality care. Although a number of WWW CAS relevant to the needs of oncology nurses have been discussed, these need to be further explored in accordance with empirical surveys of the current awareness information needs of oncology nurses. The empirical survey should follow on an introductory discussion about the benefits, scope of CAS and disadvantages as set out in this article. The exploratory work done in this article can serve as basis for empirical work.

Furthermore, LIS professionals should take up the challenge to find effective methods to deal with the problems associated with CAS, and to stimulate effective use of information collected through CAS. Such solutions should be linked to the information needs and information behaviour of oncology nurses.

\section{References}

Anderson, K.L., Bruce, S.D. (2002), "Putting your best foot forward in a challenging role: finding the resources needed to work in a freestanding radiation oncology clinic", Clinical Journal of Oncology Nursing, Vol. 6 No.4, pp.225-7.

Barta, K.M. (1995), "Information-seeking, research utilization, and barriers to research utilization of pediatric nurse educators", Journal of Professional Nursing, Vol. 11 No.1, pp.49-57.

Browne, N., Robinson, L., Richardson, A. (2002), "A Delphi study on the research priorities of European oncology nurses", European Journal of Oncology Nursing, Vol. 6 No.3, pp.133-44.

Case, D.O. (2002), Looking for Information: A Survey of Research on Information Seeking, Needs and Behavior, Academic Press, Amsterdam.

Cobb, S.C., Baird, S.B. (1999), "Oncology nurses' use of the internet for continuing education: a survey of Oncology Nursing Society Congress attendees", Journal of Continuing Education in Nursing, Vol. 30 No.5, pp.199-202.

Cogdill, K.W. (2003), "Information needs and information seeking in primary care: a study of nurse practitioners", Journal of the Medical Library Association, Vol. 91 No.2, pp.203-15.

Dervin, B. (1999), "On studying information seeking methodologically: the implications of connecting metatheory to method", Information Processing and Management, Vol. 34 pp.727-50. 
Echlin, K.N., Rees, C.E. (2002), "Information needs and information-seeking behaviors of men with prostate cancer and their partners: a review of the literature", Cancer Nursing, Vol. 25 No.1, pp.35-41.

Fidel, R., Bruce, H., Mark Pejtersen, A., Dumais, S., Grudin, J., Poltrock, S. (2000), "Collaborative information retrieval (CIR)", The New Review of Information Behaviour Research, Vol. 1 pp.235-47.

Fitch, M.I., Chart, P., Parry, N. (1998), "Information needs of nurses regarding breast disease", Canadian Oncology Nursing Journal, Vol. 8 No.3, pp.176-82.

Fourie, I. (1999), "Empowering users - current awareness on the internet", The Electronic Library, Vol. 17 No.6, pp.379-88.

Fourie, I. (2001), "Current awareness services in an electronic age - the whole picture", in Scammel, A. (Eds),Handbook of Information Management, 8th ed., Aslib, London, pp.274-306.

Fourie, I. (2002), "A review of web information-seeking/searching studies (2000-2002): implications for research in the South African context", in Bothma, T., Kaniki, A. (Eds),Progress in Library and Information Science in Southern Africa: Proceedings of the 2nd Biennial DISSAnet Conference (PROLISSA Conference), Pretoria, 24-25 October, Infuse, Pretoria, pp.49-75.

Fourie, I. (2003), "How can current awareness services (CAS) be used in the world of library acquisitions?", Online Information Review, Vol. 27 No.3, pp.183-95.

Fourie, I. (2004), "A theoretical model for studies on web information seeking behaviour: how to look and what we might see", in Bothma, T., Kaniki, A. (Eds),Progress in Library and Information Science in Southern Africa: Proceedings of the 3rd DISSAnet Conference (PROLISSA Conference), Pretoria, 28-29 October, Infuse, Pretoria, pp.6786.

French, B. (1998), "Developing skills required for evidence-based practice", Nurse Education Today, Vol. 18 No.1, pp.46-51.

Hamilton, F. (1995), Current Awareness, Current Techniques, Gower, Aldershot.

Hansen, P., Järvelin, K. (2005), "Collaborative information retrieval in an informationintensive domain", Information Processing \& Management, Vol. 41 No.5, pp.1101-19.

Hartigan, K. (2003), "Patient education: the cornerstone of successful oral chemotherapy treatment", Clinical Journal of Oncology Nursing, Vol. 7 No.6, Supplement, pp.21-4.

Housman, E.M. (1973), "Selective dissemination of information", in Cuadra, C.A., Luke, A.W. (Eds),Annual Review of Information Science and Technology, American Society for Information Science, Medford, NJ, Vol. Vol. 8 pp.221-41. 
Hughes, L.C., Hodgson, N.A., Muller, P., Robinson, L.A., McCorkle, R. (2000), "Information needs of elderly postsurgical cancer patients during the transition from hospital to home", Journal of Nursing Scholarship, Vol. 32 No.1, pp.25-30.

Hyldegård, J. (2006), "Collaborative information behaviour - exploring Kuhlthau's information search process model in a group-based educational setting", Information Processing \& Management, Vol. 42 No.1, pp.276-98.

Jenkins, J. (1997), "Educational issues related to cancer genetics", Seminars in Oncology Nursing, Vol. 13 No.2, pp.141-4.

Kemp, A. (1979), Current Awareness Services, Bingley, London.

Kuhlthau, C. (2004), Seeking Meaning: A Process Approach to Library and Information Services, Libraries Unlimited, Westport, CT.

Mahon, S.M., Williams, M. (2000), "Information needs regarding menopause. Results from a survey of women receiving cancer prevention and detection services", Cancer Nursing, Vol. 23 No.3, pp.176-85.

MedicineNet.com (2005), available at:

www.medterms.com/script/main/art.asp?articlekey=18683 (accessed 8 August 2005).

Mooney, K.H. (2004), "Promoting professional oncology nursing practice through position papers", Seminars in Oncology Nursing, Vol. 20 No.2, pp.74-88.

Nesbeitt, S.L., Gordon, R.S. (2002), The Information Professional's Guide to Career Development Online, Information Today, Medford, NJ.

Nursing Spectrum (2005), available at: www.ons.org (accessed 8 August 2005).

Pantry, S., Griffiths, P. (2002), Creating a Successful E-Information Service, Scarecrow Press, Lanham, MD, (revised and adapted by W. Oldfield, North American Editor).

Prekop, P. (2002), "A qualitative study of collaborative information seeking", Journal of Documentation, Vol. 58 No.5, pp.533-47.

Rowley, J. (1998), "Current awareness in an electronic age", Online \& CD-ROM Review, Vol. 22 No.4, pp.7-14.

Schlachta-Fairchild, L. (2001), "Telehealth: a new venue for health care delivery", Seminars in Oncology Nursing, Vol. 17 No.1, pp.34-40.

Spink, A., Jansen, B.J. (2004), Web Search: Public Searching of the Web, Kluwer Academic, Dordrecht.

Sundin, O. (2002), "Nurses' information seeking and use as participation in occupational communities", New Review of Information Behaviour Research, Vol. 3 pp.187-202. 
Tarzian, A.J., Iwata, P.A., Cohen, M.Z. (1999), "Autologous bone marrow transplantation: the patient's perspective of information needs", Cancer Nursing, Vol. 22 No.2, pp.103-10.

Thomson, H. (2000), "Information needs in the early detection phase of colorectal cancer", Canadian Oncology Nursing Journal, Vol. 10 No.1, pp.22-5.

Trench, S. (1997), "Dissemination of information", in Scammel, A. (Eds),Handbook of Special Librarianship and Information Work, 7th ed., Aslib, London, pp.285-302.

Urquhart, C., Crane, S. (1994), "Nurses' information-seeking skills and perceptions of information sources: assessment using vignettes", Journal of Information Science, Vol. 20 No.4, pp.237-46.

Vakkari, P. (2003), "Task-based information searching", in Cronin, B. (Eds),Annual Review of Information Science and Technology, Information Today, Medford, NJ, Vol. Vol. 37 pp.413-64.

Van der Molen, B. (1999), "Relating information needs to the cancer experience: 1. Information as a key coping strategy", European Journal of Cancer Care, Vol. 8 No.4, pp.238-44.

Verhey, M.P. (1999), "Information literacy in an undergraduate nursing curriculum: development, implementation and evaluation", Journal of Nursing Education, Vol. 38 No.6, pp.252-9.

Wakeham, M. (1992), "The information seeking behaviour of nurses in the UK", Information Services and Use, Vol. 12 No.2, pp.131-40.

Walton, G. (2004), "New structures and principles in health services", in Walton, G., Booth, A. (Eds),Exploiting Knowledge in Health Services, Facet Publishing, London, pp.3-15.

Whitehall, T. (1982), "Dissemination of information", in Anthony, L.J. (Eds),Handbook of Special Librarianship and Information Work, 5th ed., Aslib, London, pp.335-73.

Choo, C.W., Detlor, B., Turnbull, D. (2000), Web Work: Information Seeking and Knowledge Work on the World Wide Web, Kluwer Academic, Dordrecht.

Mahon, S.M., Williams, M. (2000), "Information needs regarding menopause. Results from a survey of women receiving cancer prevention and detection services", Cancer Nursing, Vol. 23 No.3, pp.176-85. 
openUP (March 2007)

\section{Appendix}

Table AI Examples of CAS relevant to oncology nurses

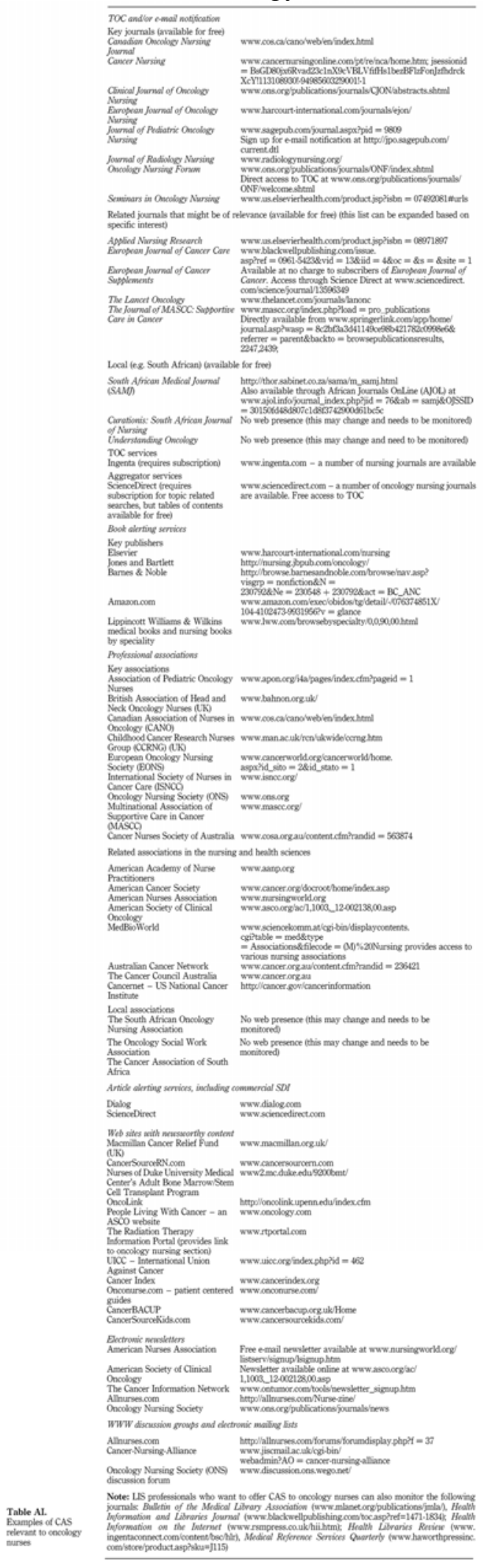




\section{About the authors}

Ina Fourie is an Associate Professor in the Department of Information Science at the University of Pretoria, South Africa. She teaches aspects of information organisation and retrieval at undergraduate and postgraduate level. Her research interests include information seeking behaviour, current awareness services, instructional design, and distance and telematic teaching. She is a member of CILIP, ASIS\&T, and a number of local associations. Ina Fourie is the corresponding author and can be contacted at: ina.fourie@up.ac.za

Retha Claasen-Veldsman is a Junior Lecturer at the Department of Information Science at the University of Pretoria, South Africa. She obtained her BA Information Science and BA Information Science Honours degrees (cum laude) at the University of Pretoria and is currently busy with her Master's degree in Development Communication. 